\title{
Sistem Reimbursement Elektronik (e-Reimbursement) Pada PT Fan Integrasi Teknologi
}

\author{
Vita Putri Anugerah $^{1)}$, Ahmad Fitriansyah ${ }^{* 2)}$, Eka Satryawati ${ }^{3)}$ \\ 1)2)3) Program Studi Sistem Informasi, Universitas Mohammad Husni Thamrin \\ ${ }^{*}$ Correspondence Author: hafaskom@gmail.com, Jakarta, Indonesia \\ DOI: https://doi.org/10.37012/jtik.v6i2.234
}

\begin{abstract}
Abstrak
Perkembangan teknologi memiliki dampak positif dan manfaat bagi penggunanya. Pemanfaatan teknologi informasi yang diimplementasikan dalam bentuk aplikasi sistem untuk mengolah data menjadi informasi yang dapat membantu organisasi dalam menghasilkan informasi yang cepat dan akurat. PT Fan Integrasi Teknologi saat ini dalam melakukan pengajuan reimbursement masih dilakukan secara manual, sehingga banyak karyawan mengeluh karena lamanya proses pencairan reimbursement dikarenakan terjadi penumpukan pengajuan reimbursement oleh karyawan yang membuat terjadinya keterlambatan dalam pengajuan laporan reimbursement bulanan yang dilakukan oleh staf keuangan ke manajer operasional. Untuk mengatasi masalah ini, peneliti mengajukan solusi dengan pembuatan sistem informasi reimbursement agar pengajuan reimbursement dapat dilakukan secara elektronik yang akhirnya akan dapat mempercepat proses pencairan reimbursement. Penelitian ini dilakukan dengan metode studi lapangan dan studi pustaka. Studi lapangan dilakukan dengan melakukan observasi secara langsung terhadap sistem yang berjalan sekaligus melakukan wawancara dengan staf keuangan yang bertugas menangani reimbursement. Studi pustaka dilakukan dengan mengumpulkan bahan pustaka terkait sistem reimbursement. Hasil penelitian berupa aplikasi sistem informasi reimbursement elektronik (e-reimbursement) yang dibangun menggunakan bahasa pemrograman PHP 7 dengan framework CodeIgniter 3.1.10 dan sistem basis data MySQL. Aplikasi menggunakan 15 file database dan melibatkan 5 aktor yaitu Staf, Staf Keuangan, Manajer Operasional, Direktur dan Administrator.
\end{abstract}

Kata Kunci: Sistem, Informasi, Reimbursement, Codeignitter

\begin{abstract}
Technology has a positive impact and benefits for its users. Utilization of information technology that is implemented in the form of system applications to process data into information that can help organizations produce information quickly and accurately. PT Fan Integrasi Teknologi is currently conducting reimbursement submissions manually, so many employees have complained that the length of the reimbursement disbursement process is due to a buildup of reimbursement submissions by employees which causes delays in submitting monthly reimbursement reports made by financial staff to operational managers. To overcome this problem, the researcher proposes a solution by making a reimbursement information system so that the submission of reimbursements can be done electronically which will ultimately be able to accelerate the process of disbursement of reimbursement. This research was conducted by the method of field study and literature study. The field study was carried out by directly observing the current system as well as conducting interviews with financial staff in charge of handling reimbursements. A literature study is done by collecting library materials related to the reimbursement system. The results of this research are in the form of an electronic reimbursement information system (e-reimbursement) that was built using the PHP 7 programming language with the CodeIgniter 3.1.10 framework and the MYSQL database system. The application uses 15 database files and involves 5 actors namely Staff, Financial Staff, Operations Managers, Directors, and Administrators.
\end{abstract}

Keywords: Systems, Information, Reimbursement, Codeignitter 


\section{PENDAHULUAN}

Perkembangan teknologi memiliki berdampak positif serta memberikan banyak manfaat bagi penggunanya. Salah satunya adalah teknologi informasi. Teknologi sistem informasi seringkali diimplementasikan dalam bentuk aplikasi sistem yang digunakan untuk mengolah data menjadi informasi. Penggunaan teknologi sistem informasi dalam bentuk aplikasi telah banyak dilakukan khususnya dalam dunia industri. Namun sampai saat ini masih ada perusahaan yang belum menerapkan teknologi sistem informasi tersebut dalam proses bisnisnya. Salah satunya terjadi pada PT Fan Integrasi Teknologi.

Sistem yang berjalan di PT Fan Integrasi Teknologi ketika karyawan melakukan pengajuan reimbursement masih dilakukan secara manual dan belum menggunakan sistem aplikasi, sehingga membuat banyak karyawan mengeluh karena lamanya proses pencairan dana reimbursement. Masalah yang terjadi pada sistem berjalan adalah proses rekapitulasi yang lama dikarenakan terjadi penumpukan dokumen pengajuan reimbursement oleh karyawan, menyebabkan keterlambatan dalam pengajuan laporan reimbursement bulanan yang dilakukan oleh staf keuangan ke manajer operasional. Akibatnya pembayaran reimbursement karyawan oleh manajer operasional diluar batas waktu pembayaran yang semestinya, karena hal tersebut banyak karyawan mengeluhkan prosedur sistem berjalan dari pengajuan reimbursement ini.

Untuk mengatasi masalah ini, peneliti mengajukan solusi dengan pembuatan sistem informasi reimbursement agar pengajuan reimbursement dapat dilakukan secara elektronik yang akhirnya akan dapat mempercepat proses pencairan reimbursement.

Perancangan adalah suatu proses yang bertujuan untuk menganalisis, menilai, memperbaiki dan menyusun suatu sistem, baik sistem fisik maupun non fisik yang optimum untuk waktu yang akan datang dengan memanfaatkan informasi yang ada (Nur \& Suyuti, 2018). Sistem didefinisikan sebagai suatu kesatuan yang terdiri dari dua atau lebih komponen atau subsistem yang berinteraksi untuk mencapai suatu tujuan (Rochaety, 2017). Menurut Gordon B. Davis, informasi adalah data yang telah diproses ke dalam suatu bentuk yang mempunyai arti bagi penerima dan memiliki nilai nyata yang dibutuhkan untuk proses pengambilan keputusan saat ini maupun saat mendatang (Rochaety, 2017). Sehingga suatu sistem informasi memiliki pengertian suatu sistem di dalam suatu organisasi yang mempertemukan kebutuhan pengolahan transaksi harian yang mendukung fungsi operasi organisasi yang bersifat manajerial dengan strategi dari suatu organisasi untuk dapat menyediakan kepada pihak luar tertentu dengan laporan-laporan yang diperlukan (Sutabri, 2016). 
Reimbursement adalah proses penggantian dana dalam nominal tertentu dari perusahaan kepada karyawan sebagai bentuk klaim atas dana yang dikeluarkan oleh karyawan untuk kepentingan perusahaan. Dalam prosesnya, setiap perusahaan akan memiliki kebijakan terkait dengan batasan dan penggunaan dana yang dapat dilakukan reimbursement.

PHP berasal dari kata "Hypertext Preprocessor", yaitu bahasa pemrograman universal untuk penanganan pembuatan dan pengembangan sebuah situs web dan bisa digunakan bersamaan dengan HTML (Mundzir, 2018). CodeIgniter adalah sebuah aplikasi open source yang berupa kerangka kerja atau framework untuk membangun website menggunakan bahasa pemrograman PHP (Sulistiono, 2018). MySQL adalah sistem manajemen database SQL yang sifatnya open source (terbuka) dan paling banyak digunakan saat ini. Sistem database MySQL mampu mendukung beberapa fitur seperti multithreaded, multi-user, dan SQL database management system (DBMS). Selain itu MySQL juga bisa dikatakan sebagai implementasi dari sistem manajemen basis data relasional (RDBMS) (Mundzir, 2018).

\section{METODE}

Metode yang akan digunakan penulis dalam penelitian ini merupakan metode Research \& Development $(\mathrm{R} \& \mathrm{D})$. Metode ini digunakan untuk menghasilkan produk tertentu dan menguji keefektifannya. Produk tidak hanya berbentuk benda atau perangkat keras (hardware), tetapi bisa juga dalam bentuk perangkat lunak (software). Untuk pengembangan sistem aplikasinya pendekatan yang digunakan adalah model Prototyping. Dengan menggunakan model prototyping peneliti dan staff keuangan dapat saling berinteraksi selama proses pembuatan sistem aplikasi, dalam hal ini peneliti menggunakan referensi tahapan metode prototype dari (Pressman \& Maxim, 2014). Berikut ini adalah beberapa tahapan metode prototype :

1. Identifikasi kebutuhan aplikasi

Melakukan diskusi dengan narasumber yaitu staf keuangan dan manajer operasional tentang kondisi saat ini dan kebutuhan aplikasi yang diinginkan.

2. Membangun Prototype

Membangun prototype dengan membuat user interface yang diinginkan oleh narasumber seperti menu, laporan, database dan input serta output yang dibutuhkan oleh narasumber.

3. Menyesuaikan Prototype

Mempresentasikan kembali kepada narasumber tentang prototype yang sudah dibuat, apakah sesuai atau tidak dengan kebutuhan. 
4. Evaluasi Prototype

Melakukan evaluasi prototype yang telah disesuaikan dengan masukan dari narasumber.

5. Menggunakan Prototype

Aplikasi e-reimbursement yang telah diuji kemudian diimplementasikan pada bagian keuangan dan siap digunakan.

\section{HASIL DAN PEMBAHASAN}

Permasalahan pada sistem yang berjalan adalah ketika karyawan mengajukan reimbursement dalam waktu yang mendekati batas akhir. Staf Keuangan harus mengecek satu persatu seluruh transaksi reimbursement yang diajukan oleh karyawan tersebut. Hal itu yang akan memakan waktu, terlebih jika beberapa karyawan melakukan reimbursement pada waktu yang sama. Dampaknya adalah pengajuan laporan pembukuan (invoice) reimbursement yang seharusnya diberikan oleh Staf Keuangan kepada Manajer Operasional menjadi mundur melewati batas waktu pengajuan. Akibatnya pembayaran reimbursement tertunda, dan sering dikeluhkan oleh karyawan. Adapun alternatif pemecahan masalah adalah merancang suatu sistem informasi berbasis web untuk memudahkan karyawan dalam mengajukan reimbursement secara langsung tanpa harus menunggu dan mengumpulkan bukti-bukti reimbursement yang telah lama, sehingga mengurangi kehilangan bukti reimbursement yang diajukan. Memudahkan Staf Keuangan dalam mengecek dan melakukan proses approval dari banyak reimbursement tiap karyawan, untuk menghindari adanya keterlambatan dalam membuat laporan kepada Manajer Operasional. Dengan system informasi, ada transparansi dalam pengajuan reimbursement karyawan, sehingga karyawan mengetahui status reimbursement yang telah diajukan telah sampai tahap mana.

Pada sistem usulan, karyawan dapat melakukan pengajuan reimbursement pada aplikasi secara online, baik melalui komputer maupun handphone melalui browser. Pengajuan yang dikirim akan masuk ke dalam list reimbursement karyawan oleh staf keuangan yang nanti akan dicek dan di-approve oleh staf keuangan. Jika pengecekan sudah sesuai format dan tidak ada kesalahan, maka staf keuangan dapat langsung menyetujui (approve) reimbursement. Namun, jika format belum sesuai dan masih ada kesalahan, staf keuangan mengembalikan data pengajuan kepada karyawan yang bersangkutan melalui proses revisi. Ketika karyawan telah melakukan revisi, maka datanya dapat dikirimkan kembali kepada staf keuangan untuk kembali dilakukan pengecekan. Jika data yang direvisi oleh karyawan masih terdapat kesalahan dan tidak sesuai dengan format, staf keuangan dapat me-reject atau menolak pengajuan tersebut. 
Untuk pengajuan reimbursement yang sudah sesuai, staf keuangan dapat meng-approve pengajuan tersebut. Kemudian pada akhir bulan staf keuangan mencetak rekapan reimbursement karyawan yang telah di-approve untuk diberikan kepada Manajer Operasional dan dilakukan proses pembayaran. Ketika sudah dilakukan pembayaran, maka Manajer Operasional akan memperbaharui status pembayaran menjadi "Telah dibayar" atau "Paid", pembaharuan status juga dapat dilakukan oleh staf keuangan berdasarkan informasi dari Manajer Operasional. Karyawan akan mengecek informasi pembayaran yang telah diterimanya. Jika pembayaran sudah sesuai dengan yang diajukan, maka karyawan dapat melakukan proses finishing pada aplikasi, jika belum sesuai maka karyawan dapat melakukan komplain melalui aplikasi.

Pada aplikasi ini akan terdapat lima aktor yaitu staf (yang mengajukan reimbursement), staf keuangan, manajer operasional, direktur dan administrator sistem. Masing-masing aktor akan mempunyai akses menu yang berbeda. Adapun use case dari masing-masing aktor dapat digambarkan sebagai berikut :

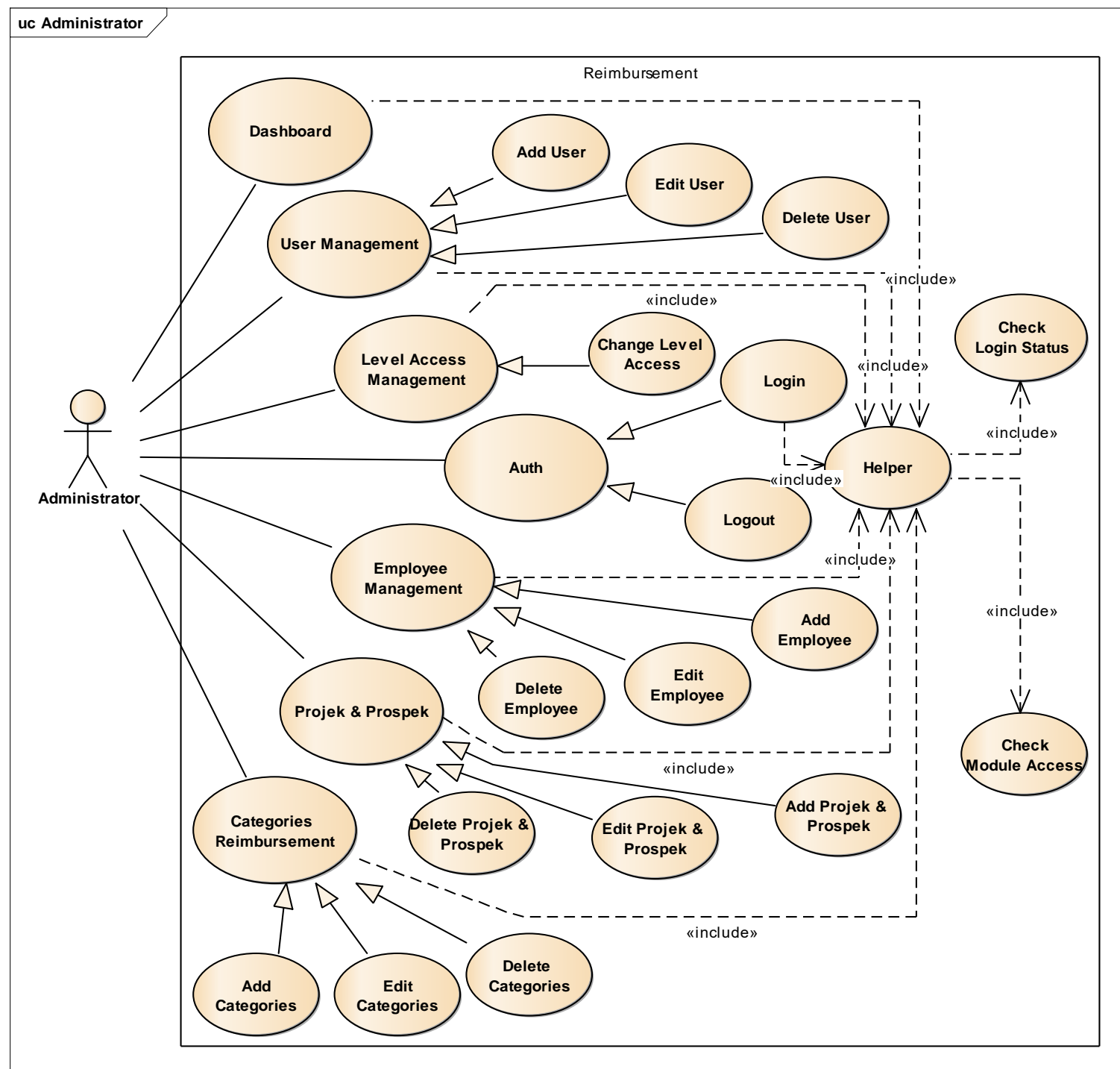

Gambar 1. Diagram Use Case Administrator 


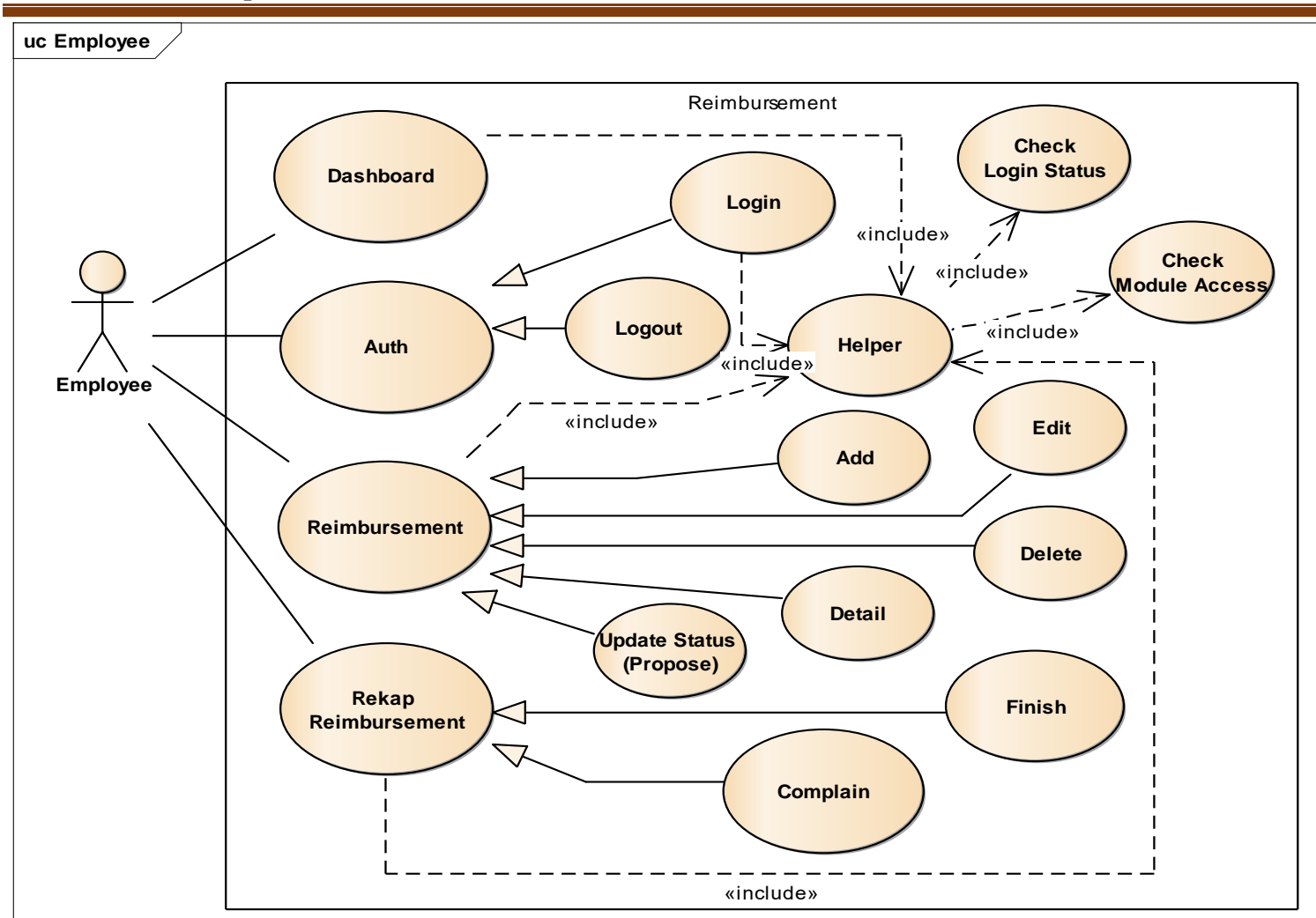

Gambar 2. Diagram Use Case Staf

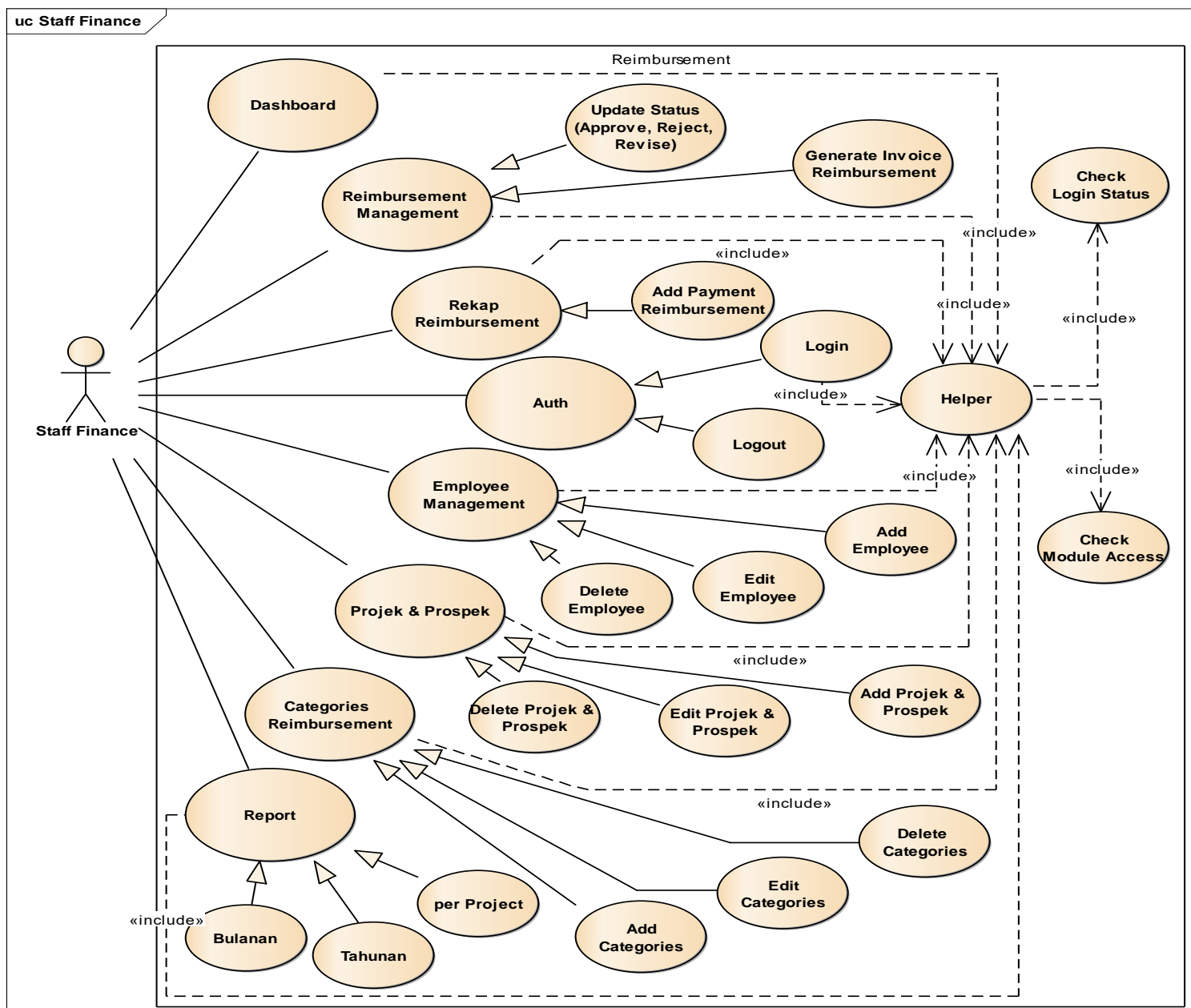

Gambar 3. Diagram Use Case Staf Keuangan 


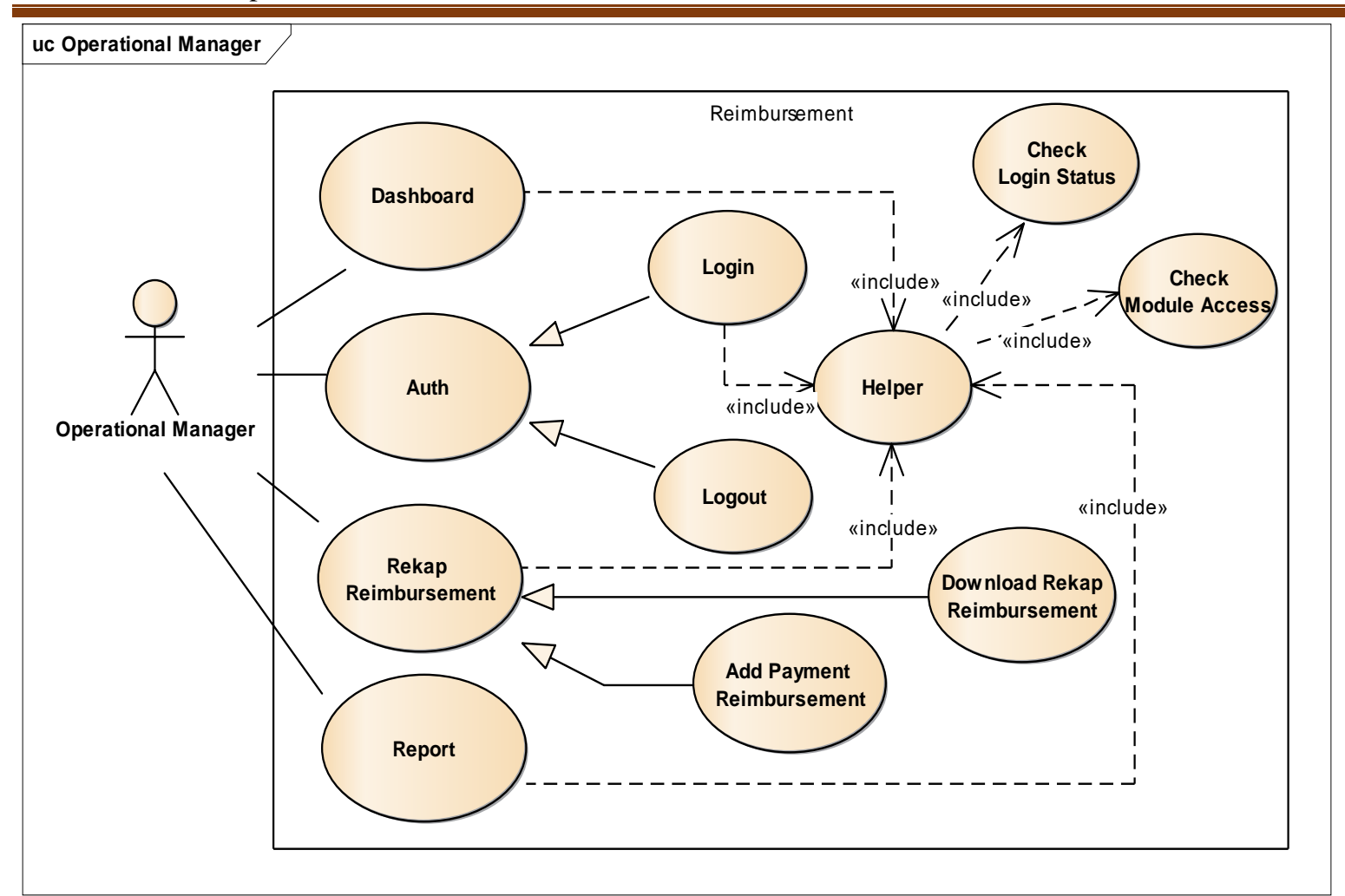

Gambar 3. Diagram Use Case Manajer Operasional

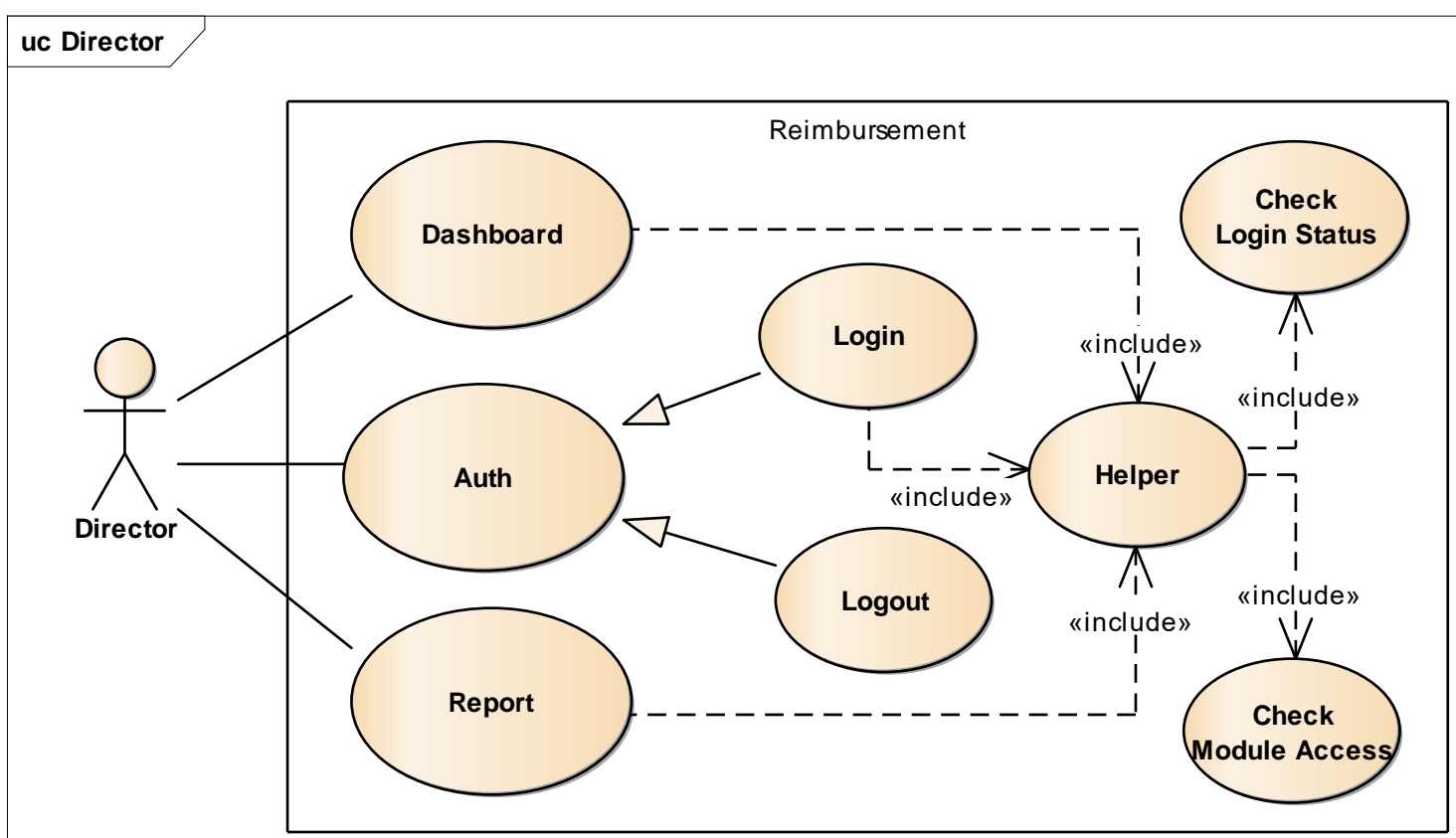

Gambar 4. Diagram Use Case Direktur

Database terdiri dari 15 file tabel yaitu Table Employee, Table User, Table Level, Table Modul, Table Level Module, Table PP (Projek \& Prospek), Table Rcategory (Reimbursement Category), Table Reim (Reimbursement), Table Reimbursement Invoice, Table Reimbursement Invoice Detail, Table Reimbursement Invoice Detail Employee, Table Reimbursement Invoice Payment, Table Reimbursement Progress, Table 

yang dibuat adalah sebagai berikut:

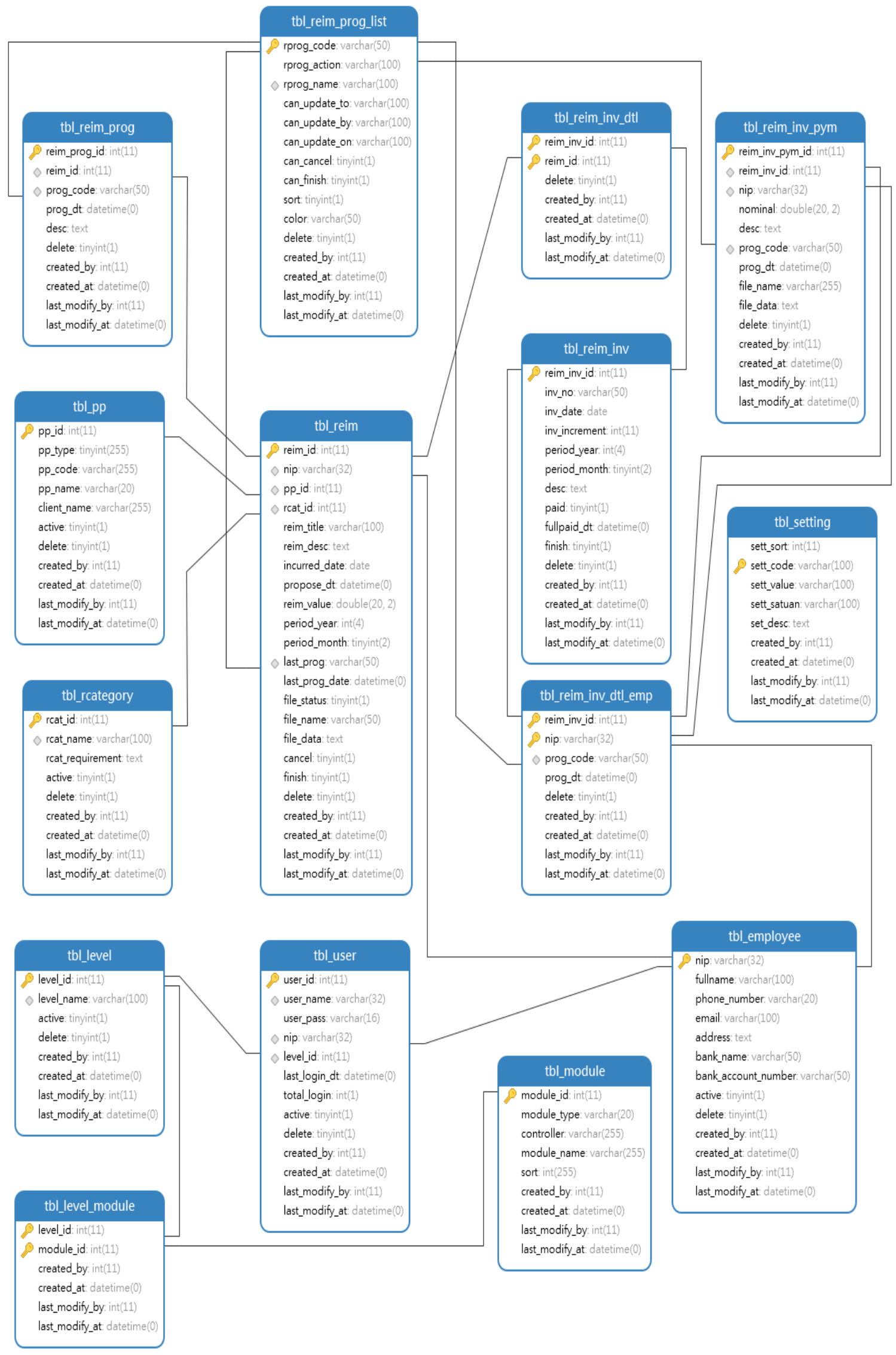

Gambar 6. Relasi Antar Tabel 
Implementasi rancangan sistem aplikasi ini menggunakan bahasa pemrograman PHP 7 dengan framework CodeIgniter 3.1.10 dan sistem basis data MySQL. Hasil implementasi rancangan antarmuka pengguna dapat dilihat sebagai berikut :

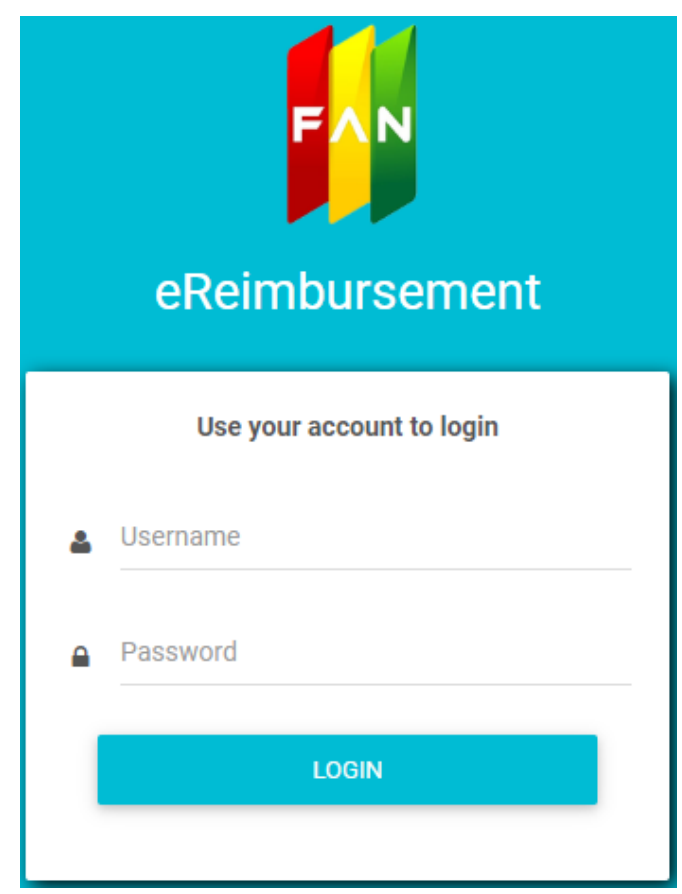

Gambar 7. Halaman Login

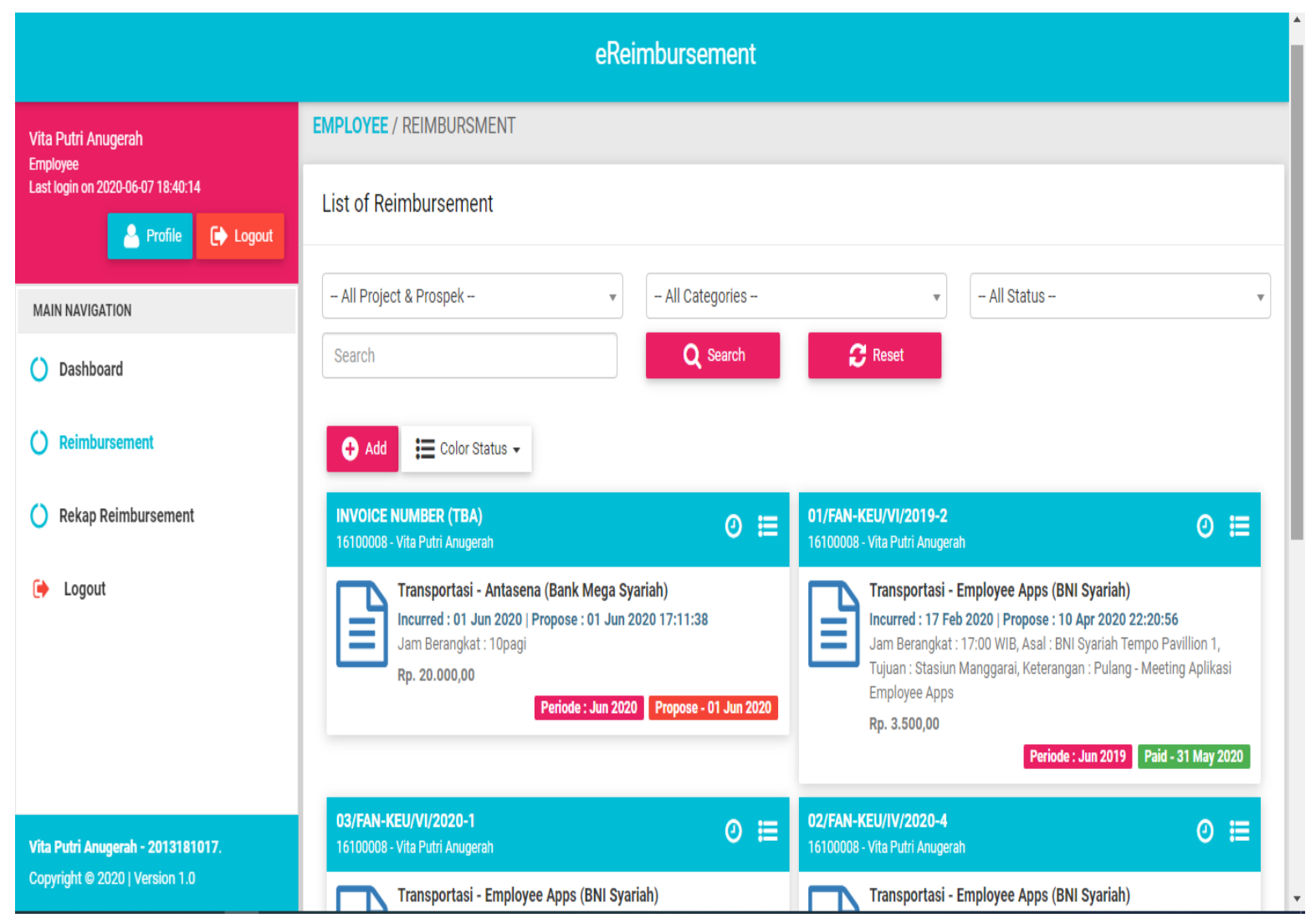

Gambar 8. Halaman List Reimbursement 


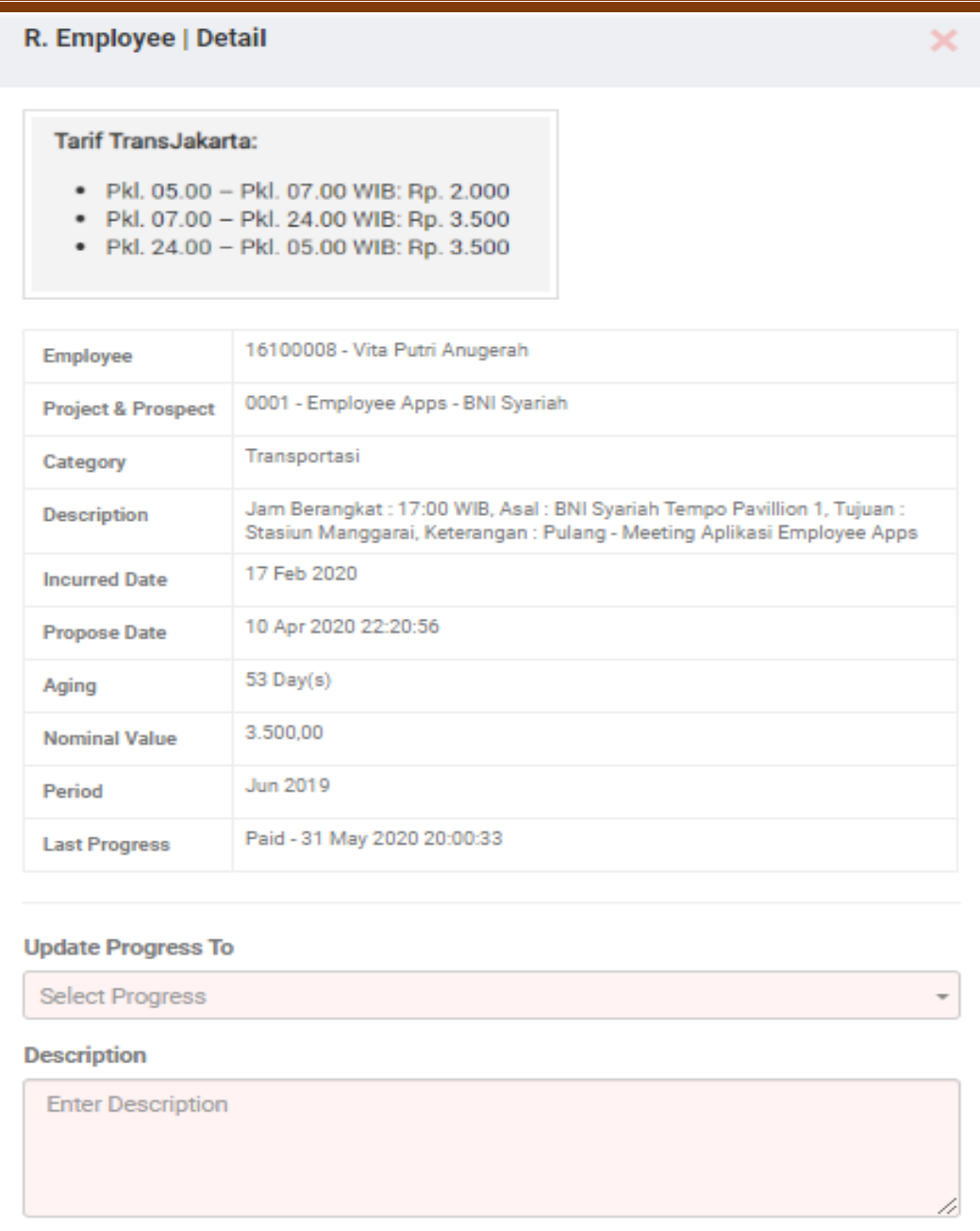

\section{回 UPDATE PROGRESS}

Gambar 9. Halaman Detail Reimbursement

\section{PT. FAN INTEGRASI TEKNOLOGI}

IT Consultant \& Services

Ruko Perumahan Taman Kota H7, Jl. Kimangun Sarkoro, Bekasi Jaya, Bekasi Timur, 17112

Bekasi, 28 Mei 2020

REIMBURSEMENT JUNI

03/FAN-KEU/VI/2020

\begin{tabular}{|c|c|l|r|}
\hline No. & NIP & \multicolumn{1}{|c|}{ Employee } & \multicolumn{1}{c|}{ Nominal } \\
\hline 1 & 16100006 & Rizki Nandito & $425.000,00$ \\
\hline 2 & 16100008 & Vita Putri Anugerah & $49.000,00$ \\
\hline & \multicolumn{2}{|c}{ TOTAL } & $474.000,00$ \\
\hline
\end{tabular}

Gambar 10. Halaman Print Invoice 


\section{KESIMPULAN DAN REKOMENDASI}

Prosedur sistem berjalan pada reimbursement masih bersifat manual, karyawan membuat dokumen pengajuan reimbursement, kemudian diberikan kepada staf keuangan. Staf keuangan akan mengecek dokumen pengajuan sebelum dilakukan persetujuan. Jika terjadi kesalahan dalam dokumen, maka akan dikembalikan kepada karyawan yang bersangkutan. Setelah staf keuangan telah selesai melakukan pengecekan dan telah melakukan persetujuan, staf keuangan akan membuat dokumen Rekapitulasi Reimbursement yang akan diberikan kepada Manajer Operasional untuk proses pembayaran reimbursement. Jika dokumen Rekapitulasi terlambat diberikan, maka akan berdampak pada kemunduran pembayaran reimbursement.

Dalam proses alur reimbursement yang berjalan, masalah yang sering dihadapi adalah pembayaran reimbursement yang sering terlambat. Setelah dilakukan evaluasi hal tersebut dikarenakan staf keuangan memerlukan waktu lebih lama untuk melakukan pengecekan dan membuat dokumen rekapitulasi reimbursement. Dengan dibuatnya sistem informasi reimbursement, karyawan dapat dengan mudah mengajukan reimbursement secara langsung tanpa harus menunggu dan mengumpulkan bukti-bukti yang rentan hilang saat akan membuat dokumen pengajuan reimbursement. Sehingga proses pengecekan dokumen pengajuan menjadi lebih efektif dan efisien dan staf keuangan dapat secara langsung membuat dokumen rekapitulasi reimbursement hanya satu klik, sehingga pemberian dokumen rekapitulasi kepada Manajer Operasional tepat waktu.

\section{REFERENSI}

Mundzir, M. F. (2018). Buku Sakti Pemrograman Web : Seri PHP. Yogyakarta: Penerbit Start Up.

Nur, R., \& Suyuti, M. A. (2018). Perancangan Mesin-Mesin Industri. Yogyakarta: Deepublish.

Pressman, R. S. ., \& Maxim, B. R. (2014). Software Engineering: A Practitioner's Approach (8th Editio). New York: McGraw-Hill Education.

Rochaety, E. (2017). Sistem Informasi Manajemen (3rd ed.). Jakarta: Mitra Wacana Media.

Sulistiono, H. (2018). Coding Mudah dengan CodeIgniter, JQuery, Bootstrap, dan Datatable. Jakarta: Elex Media Komputindo.

Sutabri, T. (2016). Sistem Informasi Manajemen (Edisi Revisi). Yogyakarta: Penerbit Andi. 